ISSN: 2162-3104 Print/ ISSN: 2166-3750 Online Volume 6, Issue 1 (2016), pp. 35-51 (C) Journal of International Students http://jistudents.org/

\title{
First Year Experience: How We Can Better Assist First-Year International Students in Higher Education
}

\author{
Zi Yan \\ Merrimack College (USA) \\ Patricia Sendall \\ Merrimack College (USA)
}

\begin{abstract}
While many American colleges and universities are providing a First Year Experience (FYE) course or program for their first year students, those programs are not often customized to take into account international students' (IS) unique challenges. Using quantitative and qualitative methods, this study evaluated a FYE course that was customized for IS in a college setting. Nineteen IS and eight domestic students (DS) who attended FYE classes completed a survey; 18 of the 19 IS were interviewed. Overall, the FYE class was successful in terms of helping IS to familiarize themselves with academic resources and expectations, understanding American culture, making more American friends, and improving their English language skills. Suggestions for future integration of IS into FYE programs are discussed.
\end{abstract}

Keywords: First year experience, Higher education, International students

The first year of college often proves to be the most difficult for many undergraduate students. Dropout rates can skyrocket when students feel disconnected or overwhelmed ( $\mathrm{Li}$, Chen, \& Duanmu, 2009). In recent years, many colleges and universities have begun to introduce First Year Experience (FYE) programs to help first year undergraduate students to better adjust to the college environment and prepare them to be more successful in their college life. The FYE course typically extends basic 
orientation content and student development across the first year. Topics range from academic skills, to wellness and stress management, and, research conducted by the Policy Center on the First Year of College found that first year seminars are offered by $90 \%$ of all four-year institutions in the U.S. (Barefoot, 2003). An environmental scan performed by the University in one study revealed that 17 of 18 competitor institutions and $100 \%$ of aspirant institutions offered an FYE (Upcraft, Gardner, \& Barefoot, 2005). Although most FYE programs in various colleges and universities share similar goals, institutions typically customize their programs to align with their university's mission and to reflect the particular needs of their student population. Previous research showed that in general, students evaluated FYE courses positively. However, the literature results are mixed, as there are significant differences between public and private colleges, between large and small colleges, and between those are focused on teaching as opposed to research (Jamelske, 2009). To the authors' knowledge, there is no research that has focused on evaluating FYE courses for a growing population on the American college campus - international students (IS).

In recent years, the number of IS in U.S. colleges and universities has increased significantly. In 2014, there were 886,052 IS enrolled in U.S. colleges and universities (Institute of International Education, 2014) - a record high. When IS come to the United States to study they face unique challenges, including lack of familiarity with American culture and the American college environment, lack of English proficiency, uncertainty about career options, and feelings of social isolation, loneliness, and even depression (Sherry \& Chui, 2010; Yan \& Cardinal, 2013). At the same time, colleges and universities have discovered many challenges in supporting the growing population of IS, including academic and non-academic problems (Sawir, 2013). Compared to domestic students (DS), IS are more dependent on the host university in various ways. For example, while DS may have other alternative sources for support (e.g., family, communities outside of universities), IS experience relatively much less sources of belongingness, connectedness, and oneness (Cho \& Yu, 2015). That said, the institutions that recruit these students are also ethically required to serve in a quasi, in loco parentis role, helping them adapt to their surroundings (Sweeton \& Davis, 2004). Offering a suitable support program for IS also increases the perceived organization support for IS, which directly increase their emotional outcomes, such as emotional stability and school-life satisfaction, and reduced psychological stress (Cho \& Yu, 2015).

So far, there are very limited first year programs in American higher education designed or customized for IS (Roy, 2013). In addition, as most research on educational curriculums are from studies of DS (Glass, 2012), it is unclear what should be included in an FYE program to best serve IS. The 
current study used quantitative and qualitative methods to evaluate the content and structure of a FYE program designed for IS in an American college. We aim to address the following research questions: 1 . What topics and contents do IS want to include in an FYE curriculum? 2. What class structure and format do IS prefer? 3. What are appropriate measures to evaluate a FYE course? Finally, based on our exploration and discussion, we formed a "recommendation list" for colleges and universities who are interested in opening or improving their FYE classes for IS. We believe that the feedback provided by IS will help other colleges and universities improve their FYE programs to better assist their IS in future.

\section{RESEARCH METHOD}

\section{Setting}

A Catholic Liberal Arts college located in the northeast USA has developed a FYE curriculum for its first-year students. It is a one-credit course and is required for all first year undergraduate IS. Each section of the course was led by a faculty member and a senior DS who served as the peer mentor. Classes met once per week for 75 minutes over a ten-week span. Prior to the class, a college-wide committee of faculty and administrators was formed to develop the FYE curriculum. The curriculum included a total of ten topics for each class. They were: academic resources, selfexploration, healthy relationships, cultural diversity, Catholic mission, alumni/philanthropy, social justice and values, academic majors/minors, careers, advising, and a a cumulating final presentation. In addition, students were required to accomplish four required activities outside the classroom. To explore the better format and outcome of the "international" FYE classes, a total of 19 IS were divided into two sections: one class with 15 IS only; the other class having 4 IS with 8 DS. The remaining 10 FYE sections were populated with DS only. Compared to other sections with DS only, the FYE for IS focused more on American culture and cultural diversity, academic resources and expectations, social support, self-exploration, and career planning. In addition, oral English skills were emphasized throughout the class as IS also indicated in the pre-assessment that they wanted to have more opportunities to practice their oral English in the FYE class.

\section{Participants and Procedure}

This study used a cross sectional study design. In the current study, IS was defined as an individual who is enrolled for credit at an accredited higher education institution in the U.S. on a temporary visa. DS was defined as a citizen or permanent resident of the U.S. who is enrolled for credit at an accredited higher education institution in the U.S. IS who were enrolled in 
the FYE program $(n=19)$ participated in the survey at the end of the FYE course. The first part of the survey included 13 items asking students to evaluate the helpfulness of different formats of the FYE class. The second component included 15 items evaluating different learning outcomes of the FYE. All items were on a 5-point Likert scale, where 1 indicated not helpful at all and 5 indicated very helpful. In addition, 18 out of the 19 IS from 6 different countries and regions participated in one-on-one interviews upon completion of the course. Interviews were conducted using a semistructured format using an interview guide. All interview questions were designed to address the study's purpose. That is, which lessons in the FYE are helpful or not-so- helpful in terms of their academic study, cultural adaptation, and college life overall; how they evaluate the format of the class, and how they think this class could be improved. Each interview lasted approximately 45 minutes. In addition, 8 DS who took the FYE course with IS (mixed-model) completed a brief survey sharing their opinions on having IS students as peers in their FYE course. The IRB at the investigators' institution approved the study.

\section{Table 1. How much did each of the following aspects of the FYE class help your learning?}

\begin{tabular}{llcc}
\hline & Topic & $M$ & $S D$ \\
\hline 1 & Community service & 4.26 & 1.20 \\
2 & Group activities in class & 4.21 & 0.92 \\
3 & Final presentations & 4.11 & 0.84 \\
4 & Weekly warm-up games/activities & 4.05 & 1.08 \\
5 & Weekly Blackboard journals & 3.95 & 0.98 \\
6 & Discussions in class & 3.95 & 1.03 \\
7 & American Food Cooking Class & 3.89 & 1.25 \\
8 & Required readings & 3.84 & 0.84 \\
9 & Individual work in class & 3.74 & 1.10 \\
10 & Presentations/lectures from course instructor(s) & 3.72 & 1.02 \\
11 & Required athletic, spiritual, and cultural activities & 3.58 & 1.22 \\
12 & Weekly volunteer presentations & 3.53 & 0.91 \\
13 & Media such as videos and film & 3.47 & 1.18 \\
\hline
\end{tabular}

\section{RESULTS}

\section{Quantitative Analysis}

A total of 30 questions were asked in the survey. The first part of the survey was designed to evaluate the helpfulness of the various components used in the FYE course (See Table 1). The second part of the 
survey evaluated learning outcomes of the FYE course for IS (See Table 2). The most helpful elements of the class as identified by the IS were: community service, group activities in class, final oral presentation, weekly icebreaker games, weekly in-class discussion, and weekly blackboard journal entries. Not-so-helpful aspects of the class were identified as: inclass video presentations, required readings, and lectures (see Table 1).

The IS also reported that the FYE was most effective in terms of helping them to "learn a lot about college," feel more comfortable communicating with their professors, adjust to American culture and to the American classroom, and to make more friends and understand more about themselves (see Table 2).

\section{Table 2. FYE Course Learning Outcomes}

\begin{tabular}{|c|c|c|c|}
\hline & The FYE course helps me.... & $M$ & $S D$ \\
\hline 1 & Learn about the College & 4.42 & 0.77 \\
\hline 2 & $\begin{array}{l}\text { Be more comfortable communicating with my } \\
\text { professors }\end{array}$ & 4.26 & 0.94 \\
\hline 3 & Better adjust to American culture & 4.21 & 0.92 \\
\hline 4 & Better adjust to the American classroom & 4.21 & 1.04 \\
\hline 5 & Make more friends & 4.16 & 0.96 \\
\hline 6 & Help me understand more about myself & 4.16 & 1.17 \\
\hline 7 & $\begin{array}{l}\text { Be more comfortable communicating with } \\
\text { American students }\end{array}$ & 4.05 & 0.92 \\
\hline 8 & $\begin{array}{l}\text { Help me understand how to build healthy } \\
\text { relationship with family, friends, and my boy/girl } \\
\text { friend }\end{array}$ & 4.05 & 1.23 \\
\hline 9 & $\begin{array}{l}\text { Help me understand social justice and why it is } \\
\text { important }\end{array}$ & 4.05 & 1.27 \\
\hline 10 & Help me more confident in my academic study & 3.95 & 1.03 \\
\hline 11 & Be more confident in my academic studies & 3.95 & 1.03 \\
\hline 12 & $\begin{array}{l}\text { Help me understand my career options and how to } \\
\text { prepare for my career }\end{array}$ & 3.89 & 1.05 \\
\hline 13 & Understand American culture & 3.89 & 1.11 \\
\hline 14 & Understand other cultures & 3.79 & 1.09 \\
\hline 15 & Better prepare for academic studies & 3.63 & 0.96 \\
\hline
\end{tabular}

\section{Qualitative Analysis}

Among the 10 topical areas, the IS identified the most helpful topics as: academic resources, healthy relationships, cultural diversity, community service, self-exploration, and academic major/minor. Topics that the 
participants suggested as least helpful were alumni relations and religion (i.e., Catholic mission).

Academic resources. The academic resources session provided students with an opportunity to actively explore the library themselves instead of being told what resources were there. Students mentioned that college provided a lot of information regarding academic resources during the orientation but failed to educate students about how to use them. In addition, some IS were from countries that do not have advanced technology widely available in schools (e.g., e-library, self-checkout), so those students needed more assistance as compared to the DS. The IS felt that they rarely used those resources until they actually went there and figured it out themselves. This "hands-on" experience was important for first-year international college students; we found that similar educational experiences should be provided. For example, Yang commented:

The academic resource session really showed us how to use those facilities on campus. It is different from the orientation. The orientation did not provide the hands-on opportunities for us, just a lot of information presented. But this session required us to go to explore ourselves, which is really helpful.

Healthy relationships. University is the place where IS begin to build new relationships with diverse groups of people (e.g., DS, instructors, etc.) from the host society. As previously revealed, one challenge for IS is social isolation due to the new environment and differing sociocultural backgrounds. Building new and maintaining previous relationships was a common challenge for all of them. In this session, some basic skills about how to maintain a good relationship with family and friends while in college were provided, followed by student discussion. Each student was asked to reveal their own experiences in terms of building and maintaining relationships. Most interviewees (89\%) agreed that this session was very helpful. This session helped them learn some basic communication skills and "college survival" skills. At the end of the session, they understood that what they were experiencing was very common among both DS and IS, and the difficult period of adjustment would be short-lived if they handled it positively.

Healthy relationship challenges for many DS are often times related to romantic relationships. Some DS feel comfortable sharing their personal experiences or opinions on this topic. However, most of the IS are more conservative or sensitive when it comes to talking about their romantic relationships, particularly those who are from Asian countries. For them, talking about family or friendship would be a much more comfortable topic. 
Those things should be kept in mind for the FYE curriculum designers or course instructors going forward.

Cultural diversity. Interviewees also revealed that the cultural diversity session was helpful. In this session, the instructor led the discussion about the importance of knowing about different cultures while attending college, and how to manage cultural shock. Students had an opportunity to introduce their own culture and share their own "cultureshock" experiences with their classmates. From the interviews, many of the IS revealed that experiencing American culture, as well as other cultures during their stay in the U.S., was very important. Cultural understanding was one of their motivations for pursuing education in the U.S.. Therefore, adding the cultural diversity or related topic in the FYE class is necessary for IS. Muham and Naan described their opinions, respectively:

Overall, getting to know American culture is very important for me. For example, I like sport a lot but I did not know about baseball, but now I learned about it from talking with my American friends in the FYE class. I learned more from the interaction (with American students) than the lectures of this class.

This class taught me about American culture. It is very helpful. For me, being away from home, sometimes I got homesick, but learning about American culture helps me to adapt to the environment here better. Also I learned about other cultures from the interactions with other IS. It makes me feel that I am not alone. It expands my knowledge too.

Community service. In the community service session, all FYE students went to different organizations in the community to provide services. Almost all of the interviewees mentioned that the one-day community service activity was their favorite from the FYE class. They explained that they had never experienced this kind of experience before (i.e., social service education). This helped them to understand more about American society and felt very fulfilled by helping others. In addition, collaborating with other students to finish a project together made them part of the team. The following quotes from Anna and Hend reflected how the IS felt about the community service portion of FYE:

We also like "Mack Gives Back" (name of the community service project). First, you have to work with people you do not know, and that is fun. We actually interacted with a lot of American students who we did not know before. At the same 
time we got a lot of work done. We helped others, and that is a great feeling.

For a lot of IS, one of the reasons they came to the U.S. is that they want to know more about American culture. Having offcampus opportunity like this opens up another window for IS to understand and explore American society and culture. The IS like this activity so much that some of them even volunteer to participate in this kind of community work again through other campus organizations.

Although activities like this are not designed to enhance IS' academic performance directly, it provides students opportunities to get to know the community, and to understand the social values that the institution, and much of American society holds. In addition, studies have shown that those service-learning experiences contribute to greater level of social responsibility and civic behavior of students (Hurtado, 2007). Including social service component into the first year curriculum will reinforce IS' overall experiences studying and living in the U.S.

Self-exploration and Academic Major/Minor. The self-exploration and academic major/minor session helped IS to understand their interests and explore their strengths and weaknesses in order to facilitate career planning. From the interview, more than half of the IS chose their current major because their parents wanted them to. Twelve out of the 18 students did not know what they wanted to do in future or whether they wanted to go back to their home country or stay in the U.S. Those IS revealed that they needed more guidance in terms of choosing a major and career planning. In addition, IS identified that they needed to understand themselves better in order to choose a suitable major. The self-exploration session used a personality assessment to match student with suitable jobs. IS found this was very helpful. In addition, each student was encouraged to share their experiences in selecting majors. A few students pointed out that listening to other students' experiences and career plans helped them choose majors and plan their future careers. We found that the discussion and interaction provided an opportunity for IS to reflect on their life goals and also strengthened their self-identity, which contributed to their cognitive and interpersonal development (Torres, 2003).

The IS pointed out that the academic major/minor and career information provided in the FYE class needs to be more specific. Since students majored in different areas, it would be helpful to assure them that different major and minor options will be introduced to them and that more 
personalized guidance will be provided during academic advisement with their faculty advisor. Grace's comment well reflected this point:

I also liked the major/minor session. It helped me find out who I am and what I am good at and what are some opportunities in future. I mean, in general, any sessions about exploring yourself, finding out what to do, who you are, and exploring the relationship are really good, and those activities with it, you know, share stories with other. I learned a lot from other people's experiences. It is a very different way to learn.

Religion and Alumni. Many colleges and universities incorporate topics related to their institution's values and mission into the FYE curriculum, as was the case here. Many IS felt it was not very helpful and unnecessary to use a whole session to address institutional mission and values. They explained that this type of information (i.e., introducing the religious background of the college, goal and mission of alumni, etc.) could be accessed on the College's website or class Blackboard site, and that they could read this material after class. That said, most IS did not mind talking about religion or other topics, as long as there is interaction with their instructor and peers. However, we should be aware that many IS do not claim any religion or religious education (e.g., Chinese students have been educated as atheists), so discussing religion is a challenge for them. Also, some students who have different religion (e.g., Muslim), so instructors should be mindful when leading students in topics involving religion.

Finally, students reported that they did not feel that the FYE course helped their academic performance directly. They explained that since students and the instructors were from different majors or areas, it was difficult to discuss any specific learning strategies or skills. However, the FYE did help them understand more about the American classroom environment and academic expectations, and better communicate with their professors and classmates. The FYE course helped them to become more competent and confident studying in American college/university that may have a positive, long-term effect on their academic performance.

\section{Format}

Pure IS model vs. mixed model? Seventeen out of the 18 students preferred the mixed-group model with American and IS together over the model with IS only. The major reasons were first, the mixed model provided them with an opportunity to understand the DS and American culture. IS were able to communicate and discuss a variety of topics with DS during 
class. Second, most IS agreed that taking the FYE class with DS provided them with a better environment to practice English. Otherwise, they tended to speak their own language in class instead of English.

The IS also pointed out that although the mixed model works better, a balanced proportion of American and international students is important. If the IS felt that there was an overwhelming number of DS in the class as a percent of IS, they would feel less comfortable and thereby reduce their courage to speak up in the classroom. In addition, IS who participated in the mixed-model class also revealed that sometimes there was a lack of communication between IS and DS. The comments of Hua and Cheng supported this belief very well. Respectively, they said

\begin{abstract}
Also, I think this class provides opportunities for IS, especially Chinese students to speak up in class, and practice English. Most Chinese students are shy, and we usually are not brave enough to speak up in class. However, this class (50/50 model) is much relaxing and I am brave enough to speak up. I feel more comfortable talking when there are a lot of other IS in class.
\end{abstract}

Most of the time, it is the IS sat together on one side of the classroom, while the DS always sat together on the other side of the classroom. I guess it is because we do not know what to talk with each other. I mean when IS sat together, we usually talk about study or academic stuff, while the DS usually talked about football or other sports that we do not know a lot.

Clearly, just having DS and IS together in a class is not enough. Instructors need to be more strategic with their delivery in order to increase interaction among students. In addition, some DS revealed that they did not know too much about the IS' cultural background, which was a barrier for them to communicate as well.

Having DS attend FYE class with IS added additional benefits. From the questionnaire we administered to the DS who took the FYE class with the IS, all eight students liked having IS in class. They revealed that they learned about different cultures from those students, which broadened their knowledge and views and increased their cultural competence. The following quotes from the DS well support this belief:

Having IS in class helped us broaden our horizons on culture and I think it helped them feel more welcome. 
Having IS in class is an eye-opener for the DS. To hear and learn about some different cultures also allows the American students to realize that the social norms are very different than from those in other countries.

I learned how it is different to live in another country and how difficult it is for them not knowing anymore here, and not speaking English (as their first language).

The mixed model is really fun. It is more interesting to interact with the IS and I always looked forward to this class.

Clearly, taking the FYE class with IS also provided benefits to the DS. This is consistent with the previous research which indicates that DS who interact more with IS during their college life reported significantly higher levels of development upon their graduation (Luo \& JamiesonDrake, 2013). Although it is not the primary goal of FYE, having IS in the FYE class can help DS develop their cultural competence and help them be more successful within an increasingly pluralistic world.

Lecture-based vs. activity-based? The current FYE class is a mix of lectures and classroom activities. The lectures are typically presented by the instructor with PowerPoint slides. Following the lecture, there were usually activities such as discussion, group activities or games that were related to the topic. When IS were asked which format they prefer, lectures or activities, 17 out of 18 students answered "activities." Their major points were: first, since most of the information in the PowerPoint slides was very straightforward, they felt that it was unnecessary to go through them in class. Instead, they suggested downloading the slides to review after class. They believed that class time was limited and should be used to do more interactive activities, such as discussions, group games, etc. This is consistent with previous research showing that students in FYE courses felt more engaged during curricular and extracurricular activities compared to traditional classroom lectures (Stebleton, Jensen, \& Peter, 2010). Almost every single interviewee liked the warm-up games at the beginning of the class (e.g., ice-breaker activities). Those activities were not necessarily related to the topic but the students felt the games helped them to interact with each other.

Second, as most IS revealed, two of the most important goals in their college life was to practice English and to understand American culture. Those goals can only be achieved through interactions with other DS. Discussion, games or group activities provide the opportunity for 
students to interact. Those opportunities in the FYE class are very different from their other academic classes. Students felt that in the FYE class, the classroom environment was more relaxed, topics were easier to comment on, and they felt less embarrassed speaking up. In sum, most IS thought that lectures were fine, but suggested keeping them very short. Most of the classroom time should be devoted to different activities and discussions. The following statements from Hua and Zhi, respectively, supported those points:

For most of us, the IS, we are science major. Most class time was devoted to lectures, so there are very limited opportunities for us to speak up or discuss in the classroom. Most of the time are just lectures. So I really hope this type of class (i.e., FYE) gives us more opportunities to interact with DS by providing more opportunities for us to speak up.

I think this class provides opportunities for IS, especially Chinese students, to speak up in class and practice English. Most of Chinese students are shy, and we usually are not brave enough to speak up in class. However, this class is much relaxing, so we are more brave (to speak up)....also, you feel more comfortable to talk while most of the classmates are IS.

Mandatory or optional? Half of the IS thought this class was very helpful and that it should be required for all first-year IS. They suggested that if it was optional, they would not be motivated to take it. However, those who supported an optional class explained that a lot of the IS attended high school in the U.S. and already had adequate language skills and knowledge of culture and academic expectations. They saw themselves as different from other first-time-in-the U.S. IS; practicing English or understanding American culture was not their priority anymore. They preferred to be treated as other American first-year college students. If FYE is optional for the students, institutions should be mindful when creating policy about who should be "required" to take FYE classes. For example, institutions may consider having a different policy for IS who have already been in the U.S. for a relatively long period compared to those who just arrived.

Student evaluation. Evaluating the FYE course is different from other academic courses. Two goals of this course are to help first year college students to better adjust to college life and to prepare them to be successful for their remaining college years. Measuring these outcomes is challenging as success is hard to define and hard to achieve within a 
relatively short period of time. One solution is to focus on "process evaluation" (i.e., implementation-based assessment) instead of "outcome evaluation." (i.e., assessing effectiveness of producing changes) For example, classroom participation, weekly journals, participating in different campus activities (i.e., cultural, religious, sport), and final presentation are good ways to measure the process outcomes. In this study, the IS felt that the evaluation format was fair. They particularly like the "journal" format as it was a good way for them to practice their writing skills and to communicate with the instructor. The journal format has been used in other FYE courses and was found effective (Stebleton et al., 2010). In addition, most of the interviewees (16/18) said they liked the final presentation where they had to present what they have learned from the FYE class. They thought the final presentation was a good motivation for them to practice their oral English and presentation skills. As most of the IS introduced their home country and culture, they also thought it was a good opportunity for them to learn about other countries and cultures.

\section{DISCUSSION AND CONCLUSION}

IS make a significant contribution to the "personality" of an institution, as well as to its financial well-being (Hegarty, 2014). At the same time, colleges and universities face unique challenges to provide high quality services to support their success in college. The FYE program provides an opportunity to address those challenges. The current study found that a tailored FYE program for IS better prepared IS for college life and contributed to their social and emotional development. FYE helped IS to become aware of college resources, better adjust to the American classroom, understand American and other cultures, become aware of academic major/minor opportunities, understand how to maintain relationships with friends and family, make more American friends, and improve their oral English. The preferred format of teaching included in-class activities, group discussions, and individual presentations. IS preferred having a balanced number of DS in the class, having one instructor and another domestic upper-class undergraduate student mentor. Lectures and videos/films were not preferred.

In terms of the purpose of the FYE class, IS are not completely unlike DS. They all experience similar challenges in the first year of college. However, IS face more challenges including: cultural and language barriers, lack of social support, etc. This study shows that a tailored FYE class successfully addressed those challenges. However, colleges and universities should also be aware that one class is not sufficient to solve all of these problems. Other supports, such as providing a writing center, 
language program, and counseling services, are essential to IS' success (Luo, \& Jamieson-Drake, 2013). Colleges and universities could also provide specific support for IS or subgroups of IS.

There is strong evidence that one of the most important ways colleges and universities contributed to students' development is by providing high-quality experiences that expose students to a diversity of intellectual, social, and cultural perspectives (Pascarella \& Terenzini, 2005). Previous research showed that FYE courses did not lead to better academic performance of students directly (Purdie \& Rosser, 2011). Instead, it contributes to students' social and cultural development. This is a very important gain for IS as they are more likely to experience problems associated with their social and cultural experiences compared to DS.

It is noteworthy that most research on FYE educational curriculums comes from studies of domestic undergraduates at American higher education institutions (Glass, 2012). As more colleges and universities have already provided or are going to provide FYE classes for IS, we should have more discussion and collect more evidence to continue evaluating the FYE program for IS. For example, what topics should be included in the FYE class for IS? How do we quantify the learning outcomes? What credentials must one have to teach this class? What type of instructor training is needed? Those questions should be discussed before, during, and after the implementation of the FYE class in order to improve the overall quality. In order for this to happen, college and university administration must provide support to the FYE program so that it can be tailored to meet unique IS needs. That said, institutions have to recognize the importance of providing those services to IS in the first place. Moreover, they should realize the importance of educating the "rest" of the campus to be culturally competent, as the success of IS also depends on the cultural competence of others, including the DS, faculty, and staff on campus. For example, the university in this study recently completed a 22-month Internationalization Lab with the American Council on Education. Two of the goals of the task force were: 1 . To foster cultural competency for faculty, staff and students; and, 2. To provide support for IS. In order to be successful, the FYE program must work in collaboration with the rest of the campus.

\section{RECOMMENDATIONS}

For colleges and universities who are interested in providing FYE or related courses to IS, we provide the following recommendations:

- Form a FYE sub-committee for IS to involve different stakeholders on campus (e.g., Office of International Programs, IS, etc.) 
- Provide more opportunities for IS to speak up in the classroom, as most of them want to improve their oral English and presentation skills through this class. Those opportunities should not be just voluntarily, but also mandatory as many IS are too reluctant to speak up.

- Create Off-campus experiential activities for students.

- Use mixed-model instruction with both DS and IS in class.

- Customize the program for IS who have different needs (e.g., those new to the U.S. vs. those who have already been in the U.S. for an extended period of time).

- Instead of having the instructor leading all sessions, use other resources on campus to join in the FYE program. For example, invite the career center to lead a session on careers and employment, have the health and wellness center lead the discussion about healthy relationships, and invite junior/senior IS undergraduates to visit class.

- Provide more discussion and interactions opportunities. Pure lecturing and in-class videos are not the preferred way of learning for either international or DS.

- Add activities outside the classroom for IS to experience American culture, e.g., American food event, such as apple picking, etc.

- Weekly journaling is an excellent way for IS to practice their English writing skills, provide feedback and track their progress in class.

We should be clear that the ultimate goal of FYE is student success. While the focus is on the first year, the goal is to prepare students for success during their four years as undergraduates and, ultimately, as graduates of the institution. This goal is even more challenging for IS as they face great barriers as compared to DS. Many institutions of higher learning in the U.S. are not yet fully prepared to serve large amounts of international students. As we continue exploring best strategies to support IS, various stakeholders on campus, particularly administration, should be mindful of this challenge. Resources must be committed to ensure the success of IS once we admit them to our programs and welcome them to our campuses. We believe that the FYE course is a natural place to begin to ensure the success of IS.

\section{REFERENCES}

Barefoot, B. (2003). Second national survey of first-year academic practices. 
Brevard, NC: Policy Center on the First Year of College. Retrieved from http://www.brevard.edu/fyc/survey/2002/findings.html

Cho, J. \& Yu, H. (2015). Roles of university support for international students in the United States: Analysis of a systematic model of university identification, university support, and psychological wellbeing. Journal of Studies in International Education, 19, 11-27.

Glass, C. R. (2012). Educational experiences associated with international students' learning, development, and positive perceptions of campus climate. Journal of Studies in International Education, 16, 228-251.

Hegarty, N. (2014). Where are we now: The presence and importance of international students to universities in the United States. The Journal of International Students, 4, 223-235.

Hurtado, S. (2007). Linking diversity with the educational and civic missions of higher education. Review of Higher Education, 30(2), 185196.

Institute of International Education. Institute of International Education. (2014). Open Doors Report on International Educational Exchange. Retrieved fromhttp://www.iie.org/opendoors

Jamelske, E. (2009). Measuring the impact of a university first-year experience program on student GPA and retention. Higher Education, 57, 373-391.

Li, Chen, \& Duanmu. (2009). Determinants of international students' academic success. Journal of Studies in International Education, 14, 389-405.

Luo, J., \& Jamieson-Drake, D. (2013). Examining the educational benefits of interacting with international students. Journal of International Students, 3(2), 85-101.

Pascarella, E. T., \& Terenzini, P. T. (2005). How college affects students: A third decade of research. Indianapolis, IN: Jossey-Bass.

Purdie, J., Rosser, V. J. (2011). Examining the academic performance and retention of first-year students in living-learning communities and firstyear experience courses. College Student Affairs Journal, 29, 95-112.

Roy, S. R. (2013). Educating Chinese, Japanese, and Korean international students: Recommendations to American professors. Journal of International Students, 3(1), 10-16.

Sawir, E. (2013). International students and internationalisation of higher education. Journal of International Students,3(1), iii-iv.

Sherry, M., T., \& Chui, W. H. (2010). International students: A vulnerable student population. Higher Education, 60, 33-46.

Stebleton, M. S., Jensen, M., \& Peter, G. (2010). Enhancing student engagement in a multidisciplinary, First-Year Experience course. College Teaching Methods \& Styles Journal, 6, 1-6. 
Sweeton, N., \& Davis, J. (2004). The evolution of in loco parentis. Journal of Student Affairs, 13, 67-72. Torres, V. (2003). Influences on ethnic identity development of Latino college students in the first two years of college. Journal of College Student Development, 44, 532-547.

Upcraft, M. L., Garner, J. N., Barefoot, B. O. (2005). Challenging \& supporting the first-year student: A handbook for improving the first year of college. San Francisco, CA: Jossey- Bass.

Yan, Z. \& Cardinal, B. J. (2013). Promoting physical activity participation among international students in American colleges and universities: A peer education approach. Journal of Physical Education, Recreation \& Dance, 84(1), 35-40.

\section{FUNDING}

The authors would like to thank the generous funding provided by the Faculty Innovation Fund from Merrimack College, which allowed for this project to occur. The authors also thank the participants for their enthusiastic participation.

Zi Yan, $\mathrm{PhD}, \mathrm{MPH}$, is an Assistant Professor of Health Sciences at Merrimack College. Email: yanz@merrimack.edu

Patricia Sendall, $\mathrm{PhD}$, is a Professor of Management at Merrimack College. Email: sendallp@merrimack.edu 